\title{
Novel oncolytic viral therapies in patients with thoracic malignancies
}

This article was published in the following Dove Press journal:

Oncolytic Virotherapy

21 December 2016

Number of times this article has been viewed

\author{
Zeeshan Ahmad \\ Robert A Kratzke \\ Department of Medicine, Division \\ of Hematology, Oncology, and \\ Transplantation, University \\ of Minnesota Medical School, \\ Minneapolis, MN, USA
}

Correspondence: Robert A Kratzke Department of Medicine, Division of Hematology, Oncology, and Transplantation, University of Minnesota Medical School, 420 Delaware Street SE, MMC 480, Minneapolis, MN 55455, USA

$\mathrm{Tel}+\mathrm{I} 6126245944$

Fax + I 6126256919

Email kratz003@umn.edu

\begin{abstract}
Oncolytic virotherapy is the use of replication-competent viruses to treat malignancies. The potential of oncolytic virotherapy as an approach to cancer therapy is based on historical evidence that certain viral infections can cause spontaneous remission of both hematologic and solid tumor malignancies. Oncolytic virotherapy may eliminate cancer cells through either direct oncolysis of infected tumor cells or indirect immune-mediated oncolysis of uninfected tumor cells. Recent advances in oncolytic virotherapy include the development of a wide variety of genetically attenuated RNA viruses with precise cellular tropism and the identification of cell-surface receptors that facilitate viral transfer to the tissue of interest. Current research is also focused on targeting metastatic disease by sustaining the release of progeny viruses from infected tumor cells and understanding indirect tumor cell killing through immune-mediated mechanisms of virotherapy. The purpose of this review is to critically evaluate recent evidence on the clinical development of tissue-specific viruses capable of targeting tumor cells and eliciting secondary immune responses in lung cancers and mesothelioma.
\end{abstract}

Keywords: lung cancer, mesothelioma, VSV, adenovirus, measles

\section{Introduction}

The potential of oncolytic virotherapy as an approach to cancer therapy is based on historical evidence of the miraculous remission of advanced malignancies after viral syndromes. ${ }^{1}$ Spontaneous remission of leukemia and lymphoma has been reported after chicken pox, measles, or hepatitis infections. ${ }^{2}$ These observations led to the first preclinical investigation to explore viruses as a treatment for cancer. One historic study published in the 1940s explored the use of murine viruses against murine tumors. ${ }^{3}$ The virus delivered intravenously at high doses proved to be antineoplastic but at the same time caused a higher level of toxicity. These findings led to initial human trials using wild-type viruses from unpurified sera and delivered as intravenous, intratumoral, or intramuscular injections; these human trials, like the mouse study, resulted in some efficacy but in significant toxicities. ${ }^{2}$ Administered viruses were neutralized by host immune responses most of the time; however, in immunocompromised individuals, tumor regression was observed, although most of the patients developed generalized viral syndrome and died subsequently. ${ }^{4}$ In one encouraging study from Osaka University in the 1970s, a dramatic antitumor response was reported in 37 of 90 terminal cancer patients treated with nonattenuated mumps virus. ${ }^{5}$ These initial studies established the potential viability of oncolytic virotherapy as an approach to cancer therapy. Here, we review recent evidence on the clinical development of tissue-specific viruses capable 
Table I Novel therapies in development

\begin{tabular}{|c|c|c|c|}
\hline Vector & Cancer type & Preclinical studies & Clinical trials \\
\hline Adenovirus & NSCLC/mesothelioma & $\begin{array}{l}\text { Anticancer effects of REIC/Dkk-3-encoding } \\
\text { adenoviral vector for the treatment of } \\
\text { NSCLC } 104\end{array}$ & $\begin{array}{l}\text { Treatment of cancer patients with a serotype } 5 / 3 \\
\text { chimeric oncolytic adenovirus expressing GMCSF } \\
\text { Safety and immunogenicity of recombinant DNA } \\
\text { and adenovirus expressing L523S protein in early } \\
\text { stage NSCLC (Phase I, recruiting) }\end{array}$ \\
\hline Coxsackievirus B3 & NSCLC & $\begin{array}{l}\text { Coxsackievirus B3 is an oncolytic virus with } \\
\text { immunostimulatory properties that is active } \\
\text { against lung adenocarcinoma }^{15}\end{array}$ & $\begin{array}{l}\text { Pembrolizumab + CVA2I in advanced NSCLC } \\
\text { (Phase I, not yet recruiting) }\end{array}$ \\
\hline Measles virus & Mesothelioma & $\begin{array}{l}\text { Oncolytic measles viruses encoding interferon } \\
\beta \text { and the thyroidal sodium iodide symporter } \\
\text { gene for mesothelioma virotherapy }{ }^{63}\end{array}$ & $\begin{array}{l}\text { Intrapleural measles virus therapy in patients with } \\
\text { malignant pleural mesothelioma (Phase I, recruiting) }\end{array}$ \\
\hline $\begin{array}{l}\text { Newcastle disease } \\
\text { virus }\end{array}$ & Mesothelioma & $\begin{array}{l}\text { Genetically engineered oncolytic Newcastle } \\
\text { disease virus effectively induces sustained } \\
\text { remission of malignant pleural mesothelioma }{ }^{101}\end{array}$ & No active clinical trial \\
\hline Seneca Valley virus & Small-cell lung cancer & $\begin{array}{l}\text { Selective tropism of Seneca Valley virus for } \\
\text { variant subtype small-cell lung cancer }{ }^{105}\end{array}$ & $\begin{array}{l}\text { Seneca Valley virus-00I after chemotherapy in } \\
\text { treating patients with extensive-stage small-cell lung } \\
\text { cancer }^{52} \text { (Phase II, active, not recruiting) }\end{array}$ \\
\hline
\end{tabular}

Abbreviations: GMCSF, granulocyte-macrophage colony-stimulating factor; NSCLC, non-small-cell lung cancer; CVA2I, coxsackievirus A2I.

of targeting tumor cells and eliciting secondary immune responses in lung cancers and mesothelioma. Numerous clinical trials are currently under way or beginning (Table 1), and these studies will be highlighted.

\section{Viral targeting of tumor cells}

The differential tropism of viruses to infect the specific tissue determines the unique pathological disease process in human beings. For instance, hepatitis B virus infects hepatocytes, mumps virus preferentially involves parotid glands and can also cause orchitis and oophoritis, human immunodeficiency virus (HIV) targets helper T-lymphocytes, and influenza virus tends to infect airway epithilium. ${ }^{4}$ The ability of oncolytic viruses to preferentially infect tumor cells is an essential element of oncolytic virotherapy. Many, if not all, wild-type viruses have the capability to infect tumor cells in general. The parvoviruses, reovirus, mumps virus, Newcastle disease virus (NDV), and Moloney leukemia virus have a natural tendency to preferentially infect cancer cells, while measles virus (MV), adenovirus, vaccinia, and herpes simplex virus can be genetically attenuated to infect cancer cells instead of human cells. ${ }^{4}$ The most common technique used to engineer viruses to selectively target cancer cells is to exploit surface markers expressed by different types of cancer cells. The epidermal growth factor receptor (EGFR), folate receptor, Her2-neu, prostate-specific antigen, CD20, COX-2, and osteoclastin are examples of surface marker selectively expressed by cancer cells; these tumor-specific surface markers can be used as a portal of entry for viruses ${ }^{6,7}$

\section{Development of attenuated viruses}

To deal with undesirable toxicity of wild-type viruses, some researchers envisioned developing attenuated viruses with preserved infectious potential but less virulence and pathogenicity. ${ }^{8}$ New technologies made it possible to preserve certain viral genes required for the antineoplastic effect and to knock out genes responsible for viral specific pathogenicity and undesirable toxicity. Numerous first-generation oncolytic viruses were selected from the breed of attenuated viruses developed to serve as vaccines. ${ }^{9}$ Further research helped to isolate the varieties of attenuated viruses with selective tropism to infect tumor cells more efficiently than normal cells. The potential to use therapeutically engineered viruses for cancer treatment led researchers to start human trials in the 1990 s. $^{2}$

\section{Oncolytic virotherapy in lung cancer}

Lung cancer is one of the most prevalent causes of death from cancers worldwide. ${ }^{10}$ It is a heterogeneous group of disorders. Non-small-cell lung cancer (NSCLC) is responsible for $\sim 80 \%$ of all reported cases of lung cancer. NSCLC is further subdivided into adenocarcinoma, squamous cell carcinoma, and large cell carcinoma. ${ }^{11}$ Although conventional chemotherapy and radiation treatment options are available, they rarely provide a cure. In addition, overall quality of life and survival of patients with NSCLC have not improved markedly in the last decade. Less common than NSCLC, small-cell lung cancer (SCLC) is considered as a very aggressive and lethal malignancy. ${ }^{12}$ Unfortunately, 
most of the patients are diagnosed with metastatic disease, and the median survival is only 9 months. ${ }^{13}$ There is an urgent need to develop more efficacious and novel treatment options to treat SCLC. ${ }^{14}$

\section{Coxsackievirus B3 (CVB3)}

CVB3 was identified as an effective and potent virotherapeutic agent against nine NSCLC cell lines in a preclinical model. It showed efficacy in in vitro screening and in vivo xenograft models in nude mice. ${ }^{15}$ The CVB3 exhibited selective tropism for NSCLC cell lines, which correlated with NSCLC expression of coxsackievirus and adenovirus receptors (CARs) and decay-accelerating factor (DAF). ${ }^{15}$ CAR is selectively overexpressed on a diverse group of human lung cancer cells but not on nonmalignant alveolar epithelial cells. ${ }^{16}$ Interestingly, the expression of DAF was found equally high in both NSCLC and normal cell lines. ${ }^{15}$ The overexpression of DAF by NSCLC cells provides a protective mechanism to counterbalance complement-mediated cytotoxicity but at the same time provides an excellent target for CVB3. ${ }^{17}$ The in vivo results of this preclinical model revealed that CVB3 induced caspase-mediated apoptosis and subsequent oncolysis in human NSCLC cells. ${ }^{15}$ The unique ability of CVB3 to induce apoptosis in NSCLC cells holds great promise. ${ }^{18,19}$ The animal model clearly elicited the regression of subcutaneous xenografts, as well as distant metastatic lesions after direct intratumoral CVB3 injection, in one of the two bilateral subcutaneous xenografts. This observation suggests that CVB3 can be used to treat metastatic disease because CVB3 replicated in one of the subcutaneous xenografts and progeny viruses disseminated through the blood or lymphatics to infect distant metastasis. ${ }^{15}$ In addition, a competent antitumor immune response triggering immune-mediated apoptotic cell death induced by CVB3 was evidenced by immunogenic changes including preapoptotic exposure to calreticulin (CRT) and extracellular adenosine triphosphate release and postapoptotic translocation of high-mobility group box protein 1 (HMGB1) from nuclei of both A549 and H1299 cells into the cytosol, activating the innate immune system, promoting inflammation, and subsequent apoptotic cell death. ${ }^{15,20,21}$ Another feature of CVB3 that enhances its therapeutic potential is its use in advanced NSCLC that is resistant to radiation and moleculartargeted therapies. A noticeable antitumor effect has been reported with intratumoral CVB3 administration against A549 adenocarcinoma xenografts, which were resistant to conventional radiation treatment and the EGFR tyrosine kinase inhibitor gefetinib. ${ }^{22,23}$

\section{Combination immunotherapy and oncolytic virotherapy}

The host immune system plays a critical role in cancer virotherapy. Neutralizing antibodies against oncolytic viruses may limit viral replication and the spread of viral progeny, thus confining the virotherapeutic effect. ${ }^{24}$ However, advancements in virotherapy can help to neutralize the immune tolerance acquired by cancer cells. In addition, the oncolytic effect of genetically engineered viruses to some extent is dependent on activation of an immune response against cancer cells infected with oncolytic virus. ${ }^{25}$ In spite of a potent antitumor immune response, tumor eradication by oncolytic viruses is usually imperfect. New technologies have devised ways to augment the immune response via arming genetically engineered adenoviruses with immunostimulatory molecules. This new concept has provided encouraging results in previous studies. ${ }^{26-29}$

The granulocyte-macrophage colony-stimulating factor (GMCSF) can augment the antitumor response through the recruitment of tumor-specific $\mathrm{CD} 8^{+} \mathrm{T}$-lymphocytes and natural killer (NK) cells. ${ }^{30,31}$ The efficacy of systemic administration of GMCSF is limited by poor penetration into the tumor microenvironment, recruitment of harmful myeloid suppressor cells, and a high toxicity profile. ${ }^{31,32}$ Consequently, the local production of GMCSF by cancer cells infected with oncolytic virus expressing GMCSF could help to minimize systemic side effects while providing sufficient levels of GMCSF in the tumor microenvironment. Local production of GMCSF can be achieved using oncolytic adenoviruses..$^{29,30}$

A chimeric oncolytic adenovirus armed with human GMCSF (Ad5/3-D24-GMCSF) has been tested in a preclinical model in hamsters as well as in 21 patients with advanced metastatic solid tumors (including NSCLC and mesothelioma) resistant to standard treatment protocols. ${ }^{33}$ Both hamsters and patients were treated in the same pattern with $4 / 5$ of the Ad5/3-D24-GMCSF doses given directly in the tumor and 1/5 injected intravenously. A starting dose of $8 \times 1010$ viral particles was administered in patients based on previously published studies. ${ }^{34}$ Patients tolerated a density of $4 \times 1011$ viral particles without grade 4 or 5 (Common Toxcitiy Criteria for Adverse Events [CTCAE]) adverse events, although mild flu-like symptoms and local pain were observed. It has been reported in the published literature that oral cyclophosphamide is associated with a decrease in the number of regulatory T-cells, which leads to a suppression of their inhibitory effect on cytotoxic T-cells and NK cells. ${ }^{35}$ To reduce tumor-induced immune tolerance and enhance oncolytic adenovirus-mediated anticancer immunotherapy, 
low-dose oral metronomic cyclophosphamide at a dose of $50 \mathrm{mg} /$ day was offered to patients without contraindications. ${ }^{35}$ The use of cyclophosphamide enhanced the antitumor effect of Ad5/3-D24-GMCSF as compared to cyclophosphamide treatment alone. Although a previous study with oncolytic vaccinia virus coding GMCSF reported elevated serum levels of GMCSF and white blood cells, ${ }^{36}$ preclinical testing of Ad5/3-D24-GMCSF revealed undetectable systemic GMCSF and white blood cells, which was indicative of restricted GMCSF release only at the site of viral infection and replication. ${ }^{33}$ Treatment with Ad5/3-D24-GMCSF revealed stable or better disease control in $67 \%$ of patients based on radiological assessment. Moreover, several patients were found to have resolution of pleural effusion and ascites, and two patients had reduced tumor marker levels; however, the utility of tumor markers is limited in the setting of oncolytic therapy as the levels can be elevated secondary to viral replication and tumor cell lysis. ${ }^{37}$ A positive viral titer was detected in the serum of 12 out of 15 patients from days 3 to 7 and even on day 58, and an increase in viral titer was noticed in eight patients as compared to day $1 .{ }^{33}$ This pattern of elevated viral titer is consistent with viral replication in prior studies as well. ${ }^{38-41}$ All patients tested exhibited an increase in neutralizing antibodies within 1-2 weeks, although there was no direct relationship between neutralizing antibody titer with viral dose, virion release in the blood, oncolytic activity, or toxicity. This observation is consistent with the results of previous clinical trials..$^{39,40,42}$ In terms of its efficacy (ie, 67\% radiological clinical benefit), this study concurs with other preclinical studies suggesting that the Ad5/3 chimeric virus might be more favorable than the Ad5 virus. ${ }^{43-51}$ In general, the results of preclinical and early clinical testing of Ad5/3D24-GMCSF are encouraging and suggest that it may have potential effectiveness in patients with advanced solid tumor cancers. ${ }^{33} \mathrm{~A}$ Phase I and II clinical trial with multiple injections of Ad5/3-D24-GMCSF in combination with low-dose metronomic cyclophosphamide is ongoing. ${ }^{33}$

Seneca Valley virus (SVV-001) has been tested in a Phase I clinical trial of cancers with neuroendocrine differentiation. ${ }^{52} \mathrm{SSV}-001$ is an oncolytic picornavirus initially discovered as a contaminant in adenovirus preserved in a laboratory. ${ }^{53,54}$ The replicative potential of the SSV-001 was tested and found to be highest in those cancer cell lines that harbor neuroendocrine characteristics, which include 13 of 23 cell lines of SCLC. ${ }^{53,55}$ In this Phase I trial, 30 patients, including six patients with SCLC, were treated with the lowest intravenous dose of SVV-001. Surprisingly, SVV001 was well tolerated without significant dose-limiting toxicities. The most promising feature of this trial was the immunohistochemical data demonstrating that viral replication was selective for tumor tissue as evidenced by negative staining in organs without cancer and positive staining in organs with metastatic lesions. Immunostaining of liver lesions clearly demonstrated intracellular staining of viral particles in cancer cells with no evidence of SSV-001 in normal liver tissue. This observation was further supported by the persistent production of SVV-001 viral titers selectively confined to those patients with metastatic SCLC. Although none of the patients demonstrated objective partial or complete antitumor response by response evaluation criteria in solid tumors (RECIST) criteria, ${ }^{56}$ one patient with chemorefractory SCLC with progressive disease experienced progressionfree survival for 10 months and remained alive over 3 years after receiving SVV-001. ${ }^{52}$ On the basis of these promising findings, a Phase II trial has been initiated to further test the safety profile, antitumor activity, and selective intratumoral viral replication of SVV-001 in SCLC. ${ }^{52}$

\section{Oncolytic virotherapy in malignant pleural mesothelioma}

Malignant pleural mesothelioma develops in the mesothelium, which encases the entire lung and helps to diminish the kinetic friction between the lungs and chest wall during the breathing cycle. ${ }^{57}$ It has been observed that even asbestos exposure of 2 months can adversely affect normal mesothelium cells and lead to malignant mesothelioma after many years. ${ }^{58}$ Malignant mesothelioma is a lethal disease with a very high fatality rate, and incidence is increasing worldwide. ${ }^{59}$ Unfortunately, the prognosis of malignant pleural mesothelioma is bleak with current treatment options including surgery, chemotherapy, and radiation treatment. ${ }^{59,60}$ Malignant mesothelioma leads to death within $8-14$ months of diagnosis. ${ }^{57}$

\section{MV}

$\mathrm{MV}$ is another effective and safe oncolytic virus. ${ }^{61}$ There is historic evidence of spontaneous tumor regression with measles infection. ${ }^{62}$ The Edmonston strain of MV has shown selective anticancer activity through syncytia formation in several cancer cell lines without infecting normal cells. ${ }^{61}$ Various preclinical studies have used oncolytic MV in a large variety of human cancers including malignant pleural mesothelioma and found enhanced cell death and improved survival. ${ }^{63-65}$ None of these preclinical models discussed the effect of neutralizing antimeasles antibodies secondary to prior infection or vaccination while using MV as oncolytic treatment. $^{66}$ 
The Schwarz MV is a live genetically attenuated MV and has been shown to preferentially infect and kill mesothelioma cells in vitro. ${ }^{67}$ This study found that MV induced cytoreduction through syncytial formation (multinuclear cellular complexes).$^{67}$ It was also observed that MV vaccine caused noticeable destruction of malignant mesothelial cells without significant lytic effect on nontransformed Met5A cells. Furthermore, the MV Edmonston strain vaccine was found to infect cancer cells through a human membrane cofactor protein, CD46. ${ }^{68} \mathrm{CD} 46$ is a member of the regulators of complement activation gene, which is located on chromosome 1 at q3.2. ${ }^{69} \mathrm{CD} 46$ has cofactor activity that helps CD46 to bind with membrane-bound $\mathrm{C} 3 \mathrm{~b}$ and $\mathrm{C} 4 \mathrm{~b}$ and facilitates $\mathrm{C} 3 \mathrm{~b}$ and $\mathrm{C} 4 \mathrm{~b}$ to be degraded by plasma serine protease (factor I).$^{70} \mathrm{In}$ this way, CD46 provides a protective mechanism to cells and prevents complement-mediated autologous cell damage. ${ }^{71} \mathrm{CD} 46$ is often expressed abundantly by tumor cells as compared to normal human cells. ${ }^{72}$ Thus, the phenomenon of expressing more CD46 in tumor cells as compared to their normal tissue counterparts represents a mechanism developmentally acquired by cancer cells via mutations to prevent complement-mediated lytic activity by the normal host immune system but at the same time make cancer cells more susceptible to infection by MV vaccine strains. ${ }^{67,73}$ Similar overexpression of CD46 by malignant pleural mesothelioma cells as compared to nontransformed mesothelial cells was also reported in this study ${ }^{67}$ One of the most exciting findings was that malignant pleural mesothelioma cells infected with MV appeared to trigger an autologous anticancer immune response. This concept of cancer immunotherapy was further evidenced by induction of apoptosis in mesothelioma cells infected with the MV Schwarz strain, which were eventually phagocytosed by dendritic cells. Furthermore, spontaneous maturation of dendritic cells was also observed after loading dendritic cells with MV-infected malignant pleural mesothelioma cells. This finding is consistent with the observation of enhanced proliferation of CD8 T-cells after priming of autologous T-cells with dendritic cells pretreated with MVinfected malignant mesothelioma cells. ${ }^{67}$

\section{Type I interferons}

Type I interferons (IFNs) have been used to trigger anticancer activity via an immune-mediated mechanism. ${ }^{74-76}$ Interferons mediate their effect through an immunoregulatory mechanism on antibody production, macrophage function, NK and T-cell activation, and angiogenesis inhibition. ${ }^{77-79}$ Type I interferons have a short half-life of $\sim 60$ minutes secondary to their nonselective binding to other tissues in addition to cancer cells, which limits their effectiveness when administered in the form of proteins. ${ }^{63}$ To enhance the efficacy of type I IFNs, gene transfer techniques have been used in the form of plasmids or viral vectors (eg, adenovirus) and studied in various tumor models including lung cancer, prostate cancer, and glioma. ${ }^{80-83}$ The adenovirus-IFNb vector has been used to treat mesothelioma in a mouse model, and a Phase I clinical trial has provided promising results in terms of safety and responsiveness in malignant pleural mesothelioma patients. ${ }^{84}$ When administered via viral vectors, type I IFN may induce an immune response against the vector itself in addition to potent antitumor effect. ${ }^{63}$

\section{Sodium ion symporter (NIS)}

Modern advancements in genetic engineering of MV have made it possible to insert therapeutic and diagnostic transgenes to generate recombinant $\mathrm{MV}$, which allows noninvasive monitoring of viral spread and replication..$^{85-88}$ The NIS gene has been used in vivo to track viral replication noninvasively in various tumor models. ${ }^{86-89}$ The human thyroidal NIS has shown the potential for noninvasive monitoring of MV-mIFNNIS propagation in vivo via radioiodine imaging. ${ }^{63}$ Numerous preclinical studies have described the ablative prospects of radioactive iodine (131I) in tumor xenografts. ${ }^{64,86,90,91}$ The unique ability of NIS to concentrate radioactive iodine suggests the possibility of using a viral vector to deliver the NIS gene in human tumors with the goal of targeted radiotherapy of tumors in near future..$^{90}$

The attenuated MV of Edmonston lineage with the mouse IFNb gene alone (MV-mIFNb) and with the thyroidal NIS gene (MV-mIFNb-NIS) has been successfully tested both in vitro and in vivo. The objective was to evaluate the influence of mIFNb on virotherapy and determine whether it enhanced the potency of MV coding for mIFNb and NIS. ${ }^{63}$ Both MV-mIFNb and MV-mIFNb-NIS successfully infected human mesothelioma cell lines, which suggested that mIFNb expression did not alter the oncolytic ability of MV to infect mesothelioma cells in vitro. The selective ability of MV-mIFNb-NIS to concentrate radioiodine (125I) in contrast to MV-mIFNb provided proof that MV-mIFNb-NIS induced NIS protein expression in targeted plasma membrane. MV-mIFNb expression enhanced the infiltration of CD68-positive immune cells two to four times greater than MV-GFP 7 days after subcutaneous MV injection into the flank of tumor-bearing nude mice. ${ }^{63}$ The anti-CD31 antibody was utilized to stain vascular endothelial cells of tumor vasculature. The vascular densities and number of CD31-positive endothelial cells were found to be decreased 7 days after intratumoral injection of MV-mIFNb or MV- 
mIFNb-NIS but not after treatment with MV-GFP or phosphate buffered saline (PBS). These observations suggest that using $\mathrm{MV}$-IFNb for virotherapy alters the tumor microenvironment by increasing immune cell infiltration and angiogenesis inhibition. Moreover, this study also revealed that human thyroidal NIS could be an effective tool in noninvasive monitoring of $\mathrm{MV}$-mIFNb-NIS propagation via radioiodine imaging. A median survival of 45 days was reported in mice treated with MV-GFP and MV-GFP-NIS $(P<0.001)$, and a median survival of just 20 days was reported in control animals treated with PBS only. In contrast, MV-mIFNb and MV-mIFN-NIS significantly reduced tumor burden and increased survival time in mice tumor xenografts, with the median survival being 65 and 60 days, respectively $(P<0.001) .{ }^{63}$

\section{NDV}

NDV is another emerging member of the oncolytic viral family. NDV was first noted to have potential oncolytic activity in the $1950 \mathrm{~s} .{ }^{92}$ Recent clinical trials have described its oncolytic efficacy and safety. ${ }^{93-95}$ The antineoplastic effect of NDV is complex and involves various cellular mechanisms. Apoptotic death of cancer cells is a direct oncolytic effect of NDV. ${ }^{96,97}$ In addition, there are indirect immune-mediated mechanisms by which it may kill tumor cells. NDV infection induces the host to secrete certain cytokines including interferons and TNF, which are responsible for the migration of NK cells, monocytes, macrophages, and sensitized T-cells to tumor microenvironment, resulting in subsequent oncolysis. ${ }^{98,99}$ The oncolytic potential and ability of NDV to induce a tumordirected immune response has been described in other clinical trials. ${ }^{100}$ The advantages of using NDV as an oncolytic virus are that humans do not harbor preexisting immunity against this avian virus and, as an RNA virus, the viral replication is confined to the cytosol, thus limiting the possibility of genetic integration with human DNA. ${ }^{98}$

NDV (F3aa) has been successfully tested both in vitro and in vivo in a preclinical study with malignant pleural mesothelioma in an orthotropic mouse model. ${ }^{101}$ It was clearly demonstrated during in vitro testing that NDV infects mesothelioma cell lines and causes significant oncolysis even at lower multiplicity of infections. To verify these encouraging results, fire fly luciferase-transduced MSTO- $211 \mathrm{H}$ cells were administered to an orthotropic pleural mesothelioma model and locally treated with NDV (F3aa)-GFP. Bioluminescence imaging was adapted as a tool to monitor tumor progression or regression in the pleural cavity. A decrease in tumor signal was noticed 1-3 days after viral injection, which was more profound at day 10 after the treatment. The group of animals who received multiple intrapleural treatments with NDV (four viral injections every other day at a dose of $1 \mathrm{e} 7$ plaque forming units (PFU) suspended in $100 \mu \mathrm{L}$ of PBS starting at days 1 and 10 after tumor implantation) revealed noticeable and higher reduction in tumor signals during the first 10 days after the initiation of treatment (days 1 and $10, P<0.01$ ) in comparison to the treatment group receiving a single intrapleural treatment. ${ }^{101}$ A significant survival benefit was reported in the multi-dose treatment group in comparison to the single-dose treatment group receiving NDV (F3aa)-GFP $(P=0.005)$. There was no significant difference in survival in both the treatment groups based on the start time of treatment (days 1 vs $10, P=0.84$ ). Moreover, NDV treatments produced no significant toxicities in experimental animals. Prior studies with avian paramyxovirus, NDV for human neuroblastoma, and melanoma cell lines have shown comparable results. ${ }^{102,103}$ This preclinical model indicates that NDV could be an effective virotherapeutic agent for the treatment of malignant pleural mesothelioma in pleural mesothelioma and the need for further investigation of NDV as an oncolytic agent for this lethal cancer. ${ }^{101}$

\section{Conclusion}

Oncolytic virotherapies are under active investigation in lung cancer and mesothelioma both in vitro and in vivo. Replication-competent viruses show great promise for treatment in thoracic cancers in the coming decade. Critical hurdles nonetheless remain, including eluding the host immune system. The final use of these novel therapies will become clearer in the very near future with the completion of ongoing clinical studies.

\section{Acknowledgments}

The authors would like to thank Michael Franklin and Manish Patel for their input and review of this article.

\section{Disclosure}

RAK has received support from Astra Zeneca and BoehringerIngelheim. The authors report no other conflicts of interest in this work.

\section{References}

1. Sze DY, Reid TR, Rose SC. Oncolytic virotherapy. JVasc Interv Radiol. 2013;24(8):1115-1122.

2. Kelly E, Russell SJ. History of oncolytic viruses: genesis to genetic engineering. Mol Ther. 2007;15(4):651-659.

3. Moore AE. Inhibition of growth of five transplantable mouse tumors by the virus of Russian Far East encephalitis. Cancer. 1951;4(2):375-382.

4. Russell SJ, Peng KW, Bell JC. Oncolytic virotherapy. Nat Biotechnol. 2012;30(7):658-670.

5. Asada T. Treatment of human cancer with mumps virus. Cancer. 1974;34(6):1907-1928. 
6. Cattaneo R, Miest T, Shashkova EV, Barry MA. Reprogrammed viruses as cancer therapeutics: targeted, armed and shielded. Nat Rev Microbiol. 2008;6(7):529-540.

7. Dorer DE, Nettelbeck DM. Targeting cancer by transcriptional control in cancer gene therapy and viral oncolysis. Adv Drug Deliv Rev. 2009;61(7-8):554-571.

8. Martuza RL, Malick A, Markert JM, Ruffner KL, Coen DM. Experimental therapy of human glioma by means of a genetically engineered virus mutant. Science. 1991;252(5007):854-856.

9. Smith ER, Chiocca EA. Oncolytic viruses as novel anticancer agents: turning one scourge against another. Expert Opin Investig Drugs. 2000;9(2):311-327

10. Jemal A, Siegel R, Ward E, Murray T, Xu J, Thun MJ. Cancer statistics, 2007. CA Cancer J Clin. 2007;57(1):43-66.

11. Zarogoulidis K, Zarogoulidis P, Darwiche K, et al. Treatment of non-small cell lung cancer (NSCLC). J Thorac Dis. 2013;5(suppl 4): S389-S396.

12. Jemal A, Siegel R, Ward E, Hao Y, Xu J, Thun MJ. Cancer statistics, 2009. CA Cancer J Clin. 2009;59(4):225-249.

13. Murray N, Turrisi AT 3rd. A review of first-line treatment for small-cell lung cancer. J Thorac Oncol. 2006;1(3):270-278.

14. Rudin CM, Hann CL, Peacock CD, Watkins DN. Novel systemic therapies for small cell lung cancer. J Natl Compr Canc Netw. 2008;6(3): 315-322.

15. Miyamoto S, Inoue H, Nakamura T, et al. Coxsackievirus B3 is an oncolytic virus with immunostimulatory properties that is active against lung adenocarcinoma. Cancer Res. 2012;72(10):2609-2621.

16. Wang Y, Wang S, Bao Y, et al. Coxsackievirus and adenovirus receptor expression in non-malignant lung tissues and clinical lung cancers. J Mol Histol. 2006;37(3-4):153-160.

17. Li L, Spendlove I, Morgan J, Durrant LG. CD55 is over-expressed in the tumour environment. Br J Cancer. 2001;84(1):80-86.

18. Carthy CM, Yanagawa B, Luo H, et al. Bcl-2 and Bcl-xL overexpression inhibits cytochrome c release, activation of multiple caspases, and virus release following coxsackievirus B3 infection. Virology. 2003; 313(1):147-157.

19. Martin U, Jarasch N, Nestler M, et al. Antiviral effects of pan-caspase inhibitors on the replication of coxsackievirus B3. Apoptosis. 2007; 12(3):525-533.

20. Zitvogel L, Kepp O, Senovilla L, Menger L, Chaput N, Kroemer G. Immunogenic tumor cell death for optimal anticancer therapy: the calreticulin exposure pathway. Clin Cancer Res. 2010;16(12):3100-3104.

21. Gauley J, Pisetsky DS. The translocation of HMGB1 during cell activation and cell death. Autoimmunity. 2009;42(4):299-301.

22. Guo WF, Lin RX, Huang J, et al. Identification of differentially expressed genes contributing to radioresistance in lung cancer cells using microarray analysis. Radiat Res. 2005;164(1):27-35.

23. Janmaat ML, Rodriguez JA, Gallegos-Ruiz M, Kruyt FA, Giaccone G. Enhanced cytotoxicity induced by gefitinib and specific inhibitors of the Ras or phosphatidyl inositol-3 kinase pathways in non-small cell lung cancer cells. Int J Cancer. 2006;118(1):209-214.

24. Zaiss AK, Machado HB, Herschman HR. The influence of innate and pre-existing immunity on adenovirus therapy. J Cell Biochem. 2009; 108(4):778-790.

25. Qiao J, Kottke T, Willmon C, et al. Purging metastases in lymphoid organs using a combination of antigen-nonspecific adoptive $\mathrm{T}$ cell therapy, oncolytic virotherapy and immunotherapy. Nat Med. 2008;14(1):37-44.

26. Hermiston T. Gene delivery from replication-selective viruses: arming guided missiles in the war against cancer. $J$ Clin Invest. 2000; 105(9):1169-1172.

27. Ramesh N, Ge Y, Ennist DL, et al. CG0070, a conditionally replicating granulocyte macrophage colony-stimulating factor-armed oncolytic adenovirus for the treatment of bladder cancer. Clin Cancer Res. 2006;12(1):305-313.

28. Cerullo V, Pesonen S, Diaconu I, et al. Oncolytic adenovirus coding for granulocyte macrophage colony-stimulating factor induces antitumoral immunity in cancer patients. Cancer Res. 2010;70(11):4297-4309.
29. Chang J, Zhao X, Wu X, et al. A Phase I study of KH901, a conditionally replicating granulocyte-macrophage colony-stimulating factor: armed oncolytic adenovirus for the treatment of head and neck cancers. Cancer Biol Ther. 2009;8(8):676-682.

30. Dranoff G. GM-CSF-secreting melanoma vaccines. Oncogene. 2003; 22(20):3188-3192.

31. Arellano M, Lonial S. Clinical uses of GM-CSF, a critical appraisal and update. Biologics. 2008;2(1):13-27.

32. Serafini P, Carbley R, Noonan KA, Tan G, Bronte V, Borrello I. Highdose granulocyte-macrophage colony-stimulating factor-producing vaccines impair the immune response through the recruitment of myeloid suppressor cells. Cancer Res. 2004;64(17):6337-6343.

33. Koski A, Kangasniemi L, Escutenaire S, et al. Treatment of cancer patients with a serotype $5 / 3$ chimeric oncolytic adenovirus expressing GMCSF. Mol Ther. 2010;18(10):1874-1884.

34. Kirn D. Clinical research results with d11520 (Onyx-015), a replicationselective adenovirus for the treatment of cancer: what have we learned? Gene Ther. 2001;8(2):89-98.

35. Ghiringhelli F, Menard C, Puig PE, et al. Metronomic cyclophosphamide regimen selectively depletes $\mathrm{CD} 4+\mathrm{CD} 25+$ regulatory $\mathrm{T}$ cells and restores $\mathrm{T}$ and $\mathrm{NK}$ effector functions in end stage cancer patients. Cancer Immunol Immunother. 2007;56(5):641-648.

36. Park BH, Hwang T, Liu TC, et al. Use of a targeted oncolytic poxvirus, JX-594, in patients with refractory primary or metastatic liver cancer: a phase I trial. Lancet Oncol. 2008;9(6):533-542.

37. Turunen TMO, Nokisalmi P, Cerullo V, et al. Effect of oncolytic adenovirus on tumor marker levels in cancer patients and in preclinical test systems. Mol Ther. 2009;17(S1):S110. [Abstract].

38. Alemany R, Suzuki K, Curiel DT. Blood clearance rates of adenovirus type 5 in mice. $J$ Gen Virol. 2000;81(pt 11):2605-2609.

39. Nemunaitis J, Khuri F, Ganly I, et al. Phase II trial of intratumoral administration of ONYX-015, a replication-selective adenovirus, in patients with refractory head and neck cancer. J Clin Oncol. 2001;19(2):289-298.

40. Galanis E, Okuno SH, Nascimento AG, et al. Phase I-II trial of ONYX015 in combination with MAP chemotherapy in patients with advanced sarcomas. Gene Ther. 2005;12(5):437-445.

41. Reid T, Galanis E, Abbruzzese J, et al. Hepatic arterial infusion of a replication-selective oncolytic adenovirus (d11520): phase II viral, immunologic, and clinical endpoints. Cancer Res. 2002;62(21):6070-6079.

42. Yu W, Fang H. Clinical trials with oncolytic adenovirus in China. Curr Cancer Drug Targets. 2007;7(2):141-148.

43. Kanerva A, Hemminki A. Modified adenoviruses for cancer gene therapy. Int J Cancer. 2004;110(4):475-480.

44. Kanerva A, Zinn KR, Chaudhuri TR, et al. Enhanced therapeutic efficacy for ovarian cancer with a serotype 3 receptor-targeted oncolytic adenovirus. Mol Ther. 2003;8(3):449-458.

45. Volk AL, Rivera AA, Kanerva A, et al. Enhanced adenovirus infection of melanoma cells by fiber-modification: incorporation of RGD peptide or Ad5/3 chimerism. Cancer Biol Ther. 2003;2(5):511-515.

46. Zheng S, Ulasov IV, Han Y, Tyler MA, Zhu ZB, Lesniak MS. Fiberknob modifications enhance adenoviral tropism and gene transfer in malignant glioma. $J$ Gene Med. 2007;9(3):151-160.

47. Ranki T, Sarkioja M, Hakkarainen T, von Smitten K, Kanerva A, Hemminki A. Systemic efficacy of oncolytic adenoviruses in imagableorthotopic models of hormone refractory metastatic breast cancer. Int J Cancer. 2007;121(1):165-174.

48. Sarkioja M, Kanerva A, Salo J, et al. Noninvasive imaging for evaluation of the systemic delivery of capsid-modified adenoviruses in an orthotopic model of advanced lung cancer. Cancer. 2006;107(7): $1578-1588$.

49. Kangasniemi L, Kiviluoto T, Kanerva A, et al. Infectivity-enhanced adenoviruses deliver efficacy in clinical samples and orthotopic models of disseminated gastric cancer. Clin Cancer Res. 2006;12(10): 3137-3144.

50. Guse K, Ranki T, Ala-Opas M, et al. Treatment of metastatic renal cancer with capsid-modified oncolytic adenoviruses. Mol Cancer Ther. 2007;6(10):2728-2736. 
51. Kanerva A, Mikheeva GV, Krasnykh V, et al. Targeting adenovirus to the serotype 3 receptor increases gene transfer efficiency to ovarian cancer cells. Clin Cancer Res. 2002;8(1):275-280.

52. Rudin CM, Poirier JT, Senzer NN, et al. Phase I clinical study of Seneca Valley Virus (SVV-001), a replication-competent picornavirus, in advanced solid tumors with neuroendocrine features. Clin Cancer Res. 2011;17(4):888-895.

53. Reddy PS, Burroughs KD, Hales LM, et al. Seneca Valley virus, a systemically deliverable oncolytic picornavirus, and the treatment of neuroendocrine cancers. J Natl Cancer Inst. 2007;99(21): 1623-1633.

54. Venkataraman S, Reddy SP, Loo J, Idamakanti N, Hallenbeck PL, Reddy VS. Structure of Seneca Valley Virus-001: an oncolytic picornavirus representing a new genus. Structure. 2008;16(10):1555-1561.

55. Wadhwa L, Hurwitz MY, Chevez-Barrios P, Hurwitz RL. Treatment of invasive retinoblastoma in a murine model using an oncolytic picornavirus. Cancer Res. 2007;67(22):10653-10656.

56. Therasse P, Arbuck SG, Eisenhauer EA, et al; European Organization for Research and Treatment of Cancer, National Cancer Institute of the United States, National Cancer Institute of Canada. New guidelines toevaluate the response to treatment in solid tumours. J Natl Cancer Inst. 2000;92(3):205-216.

57. Robinson BW, Musk AW, Lake RA. Malignant mesothelioma. Lancet. 2005;366(9483):397-408.

58. Neri M, Ugolini D, Dianzani I, et al. Genetic susceptibility to malignant pleural mesothelioma and other asbestos-associated diseases. Mutat Res. 2008;659(1-2):126-136.

59. Muers MF, Stephens RJ, Fisher P, et al. Active symptom control with or without chemotherapy in the treatment of patients with malignant pleural mesothelioma (MS01): a multicentrerandomised trial. Lancet. 2008;371(9625):1685-1694.

60. Vogelzang NJ. Chemotherapy for malignant pleural mesothelioma. Lancet. 2008;371(9625):1640-1642.

61. Blechacz B, Russell SJ. Measles virus as an oncolytic vector platform. Curr Gene Ther. 2008;8(3):162-175.

62. Bluming AZ, Ziegler JL. Regression of Burkitt's lymphoma in association with measles infection. Lancet. 1971;2(7715):105-106.

63. Li H, Peng KW, Dingli D, Kratzke RA, Russell SJ. Oncolytic measles viruses encoding interferon beta and the thyroidal sodium iodide symporter gene for mesothelioma virotherapy. Cancer Gene Ther. 2010;17(8):550-558.

64. Msaouel P, Iankov ID, Allen C, et al. Engineered measles virus as a novel oncolytic therapy against prostate cancer. Prostate. 2009; 69(1):82-91.

65. Grote D, Russell SJ, Cornu TI, et al. Live attenuated measles virus induces regression of human lymphoma xenografts in immunodeficient mice. Blood. 2001;97(12):3746-3754.

66. Patel MR, Kratzke RA. Oncolytic virus therapy for cancer: the first wave of translational clinical trials. Transl Res. 2013;161(4):355-364.

67. Gauvrit A, Brandler S, Sapede-Peroz C, Boisgerault N, Tangy F, Gregoire M. Measles virus induces oncolysis of mesothelioma cells and allows dendritic cells to cross-prime tumor-specific CD8 response. Cancer Res. 2008;68(12):4882-4892.

68. Naniche D, Varior-Krishnan G, Cervoni F, et al. Human membrane cofactor protein (CD46) acts as a cellular receptor for measles virus. J Virol. 1993;67(10):6025-6032.

69. Lublin DM, Liszewski MK, Post TW, et al. Molecular cloning and chromosomal localization of human membrane cofactor protein (MCP). Evidence for inclusion in the multigene family of complementregulatory proteins. J Exp Med. 1988;168(1):181-194.

70. Liszewski MK, Post TW, Atkinson JP. Membrane cofactor protein (MCP or CD46): newest member of the regulators of complement activation gene cluster. Annu Rev Immunol. 1991;9:431-455.

71. Lublin DM, Coyne KE. Phospholipid-anchored and transmembrane versions of either decay-accelerating factor or membrane cofactor protein show equal efficiency in protection from complement-mediated cell damage. J Exp Med. 1991;174(1):35-44.
72. Fishelson Z, Donin N, Zell S, Schultz S, Kirschfink M. Obstacles to cancer immunotherapy: expression of membrane complement regulatory proteins (mCRPs) in tumors. Mol Immunol. 2003;40(2-4): 109-123.

73. Varsano S, Rashkovsky L, Shapiro H, Ophir D, Mark-Bentankur T. Human lung cancer cell lines express cell membrane complement inhibitory proteins and are extremely resistant to complement-mediated lysis; a comparison with normal human respiratory epithelium in vitro, and an insight into mechanism(s) of resistance. Clin Exp Immunol. 1998;113(2):173-182.

74. Kantarjian HM, Talpaz M, O'Brien S, et al. Survival benefit with imatinibmesylate versus interferon-alpha-based regimens in newly diagnosed chronic-phase chronic myelogenous leukemia. Blood. 2006;108(6):1835-1840.

75. Ravandi F, Estrov Z, Kurzrock R, Breitmeyer JB, Maschek BJ, Talpaz M. A phase I study of recombinant interferon-beta in patients with advanced malignant disease. Clin Cancer Res. 1999;5(12):3990-3998.

76. Ravandi F, Rytting ME, Osmon C, et al. Phase II trial of 5-fluorouracil, folinic acid and recombinant alpha-2a-interferon in patients with advanced colorectal cancer. Anticancer Drugs. 1999;10(6): 519-524.

77. Chan CW, Crafton E, Fan HN, et al. Interferon-producing killer dendritic cells provide a link between innate and adaptive immunity. Nat Med. 2006;12(2):207-213.

78. Le Bon A, Tough DF. Links between innate and adaptive immunity via type I interferon. Curr Opin Immunol. 2002;14(4):432-436.

79. Brem H, Gresser I, Grosfeld J, Folkman J. The combination of antiangiogenic agents to inhibit primary tumor growth and metastasis. $J$ Pediatr Surg. 1993;28(10):1253-1257.

80. Natsume A, Tsujimura K, Mizuno M, Takahashi T, Yoshida J. IFN-beta gene therapy induces systemic antitumor immunity against malignant glioma. J Neurooncol. 2000;47(2):117-124.

81. Sakurai F, Terada T, Maruyama M, et al. Therapeutic effect of intravenous delivery of lipoplexes containing the interferon-beta gene and poly I: poly $\mathrm{C}$ in a murine lung metastasis model. Cancer Gene Ther. 2003;10(9):661-668.

82. Cao G, Su J, Lu W, et al. Adenovirus-mediated interferon-beta gene therapy suppresses growth and metastasis of human prostate cancer in nude mice. Cancer Gene Ther. 2001;8(7):497-505.

83. Natsume A, Mizuno M, Ryuke Y, Yoshida J. Antitumor effect and cellular immunity activation by murine interferon-beta gene transfer against intracerebral glioma in mouse. Gene Ther. 1999;6(9):1626-1633.

84. Sterman DH, Recio A, Carroll RG, et al. A phase I clinical trial of single-dose intrapleural IFN-beta gene transfer for malignant pleural mesothelioma and metastatic pleural effusions: high rate of antitumor immune responses. Clin Cancer Res. 2007;13(15 pt 1):4456-4466.

85. Nakamura T, Peng KW, Harvey M, et al. Rescue and propagation of fully retargeted oncolytic measles viruses. Nat Biotechnol. 2005;23(2):209-214.

86. Dingli D, Peng KW, Harvey ME, et al. Image-guided radiovirotherapy for multiple myeloma using a recombinant measles virus expressing the thyroidal sodium iodide symporter. Blood. 2004;103(5):1641-1646.

87. Carlson SK, Classic KL, Hadac EM, et al. Quantitative molecular imaging of viral therapy for pancreatic cancer using an engineered measles virus expressing the sodium-iodide symporter reporter gene. AJR Am J Roentgenol. 2009;192(1):279-287.

88. Myers RM, Greiner SM, Harvey ME, et al. Preclinical pharmacology and toxicology of intravenous MV-NIS, an oncolytic measles virus administered with or without cyclophosphamide. Clin Pharmacol Ther. 2007;82(6):700-710.

89. Carlson SK, Classic KL, Hadac EM, et al. In vivo quantitation of intratumoral radioisotope uptake using micro-single photon emission computed tomography/computed tomography. Mol Imaging Biol. 2006;8(6):324-332.

90. Boland A, Ricard M, Opolon P, et al. Adenovirus-mediated transfer of the thyroid sodium/iodide symporter gene into tumors for a targeted radiotherapy. Cancer Res. 2000;60(13):3484-3492. 
91. Cho JY, Shen DH, Yang W, et al. In vivo imaging and radioiodine therapy following sodium iodide symporter gene transfer in animal model of intracerebral gliomas. Gene Ther. 2002;9(17):1139-1145.

92. Flanagan AD, Love R, Tesar W. Propagation of Newcastle disease virus in Ehrlich ascites cells in vitro and in vivo. Proc Soc Exp Biol Med. 1955;90(1):82-86.

93. Lorence RM, Pecora AL, Major PP, et al. Overview of phase I studies of intravenous administration of PV701, an oncolytic virus. Curr Opin Mol Ther. 2003;5(6):618-624.

94. Karcher J, Dyckhoff G, Beckhove P, et al. Antitumor vaccination in patients with head and neck squamous cell carcinomas with autologous virus-modified tumor cells. Cancer Res. 2004;64(21):8057-8061.

95. Steiner HH, Bonsanto MM, Beckhove P, et al. Antitumor vaccination of patients with glioblastoma multiforme: a pilot study to assess feasibility, safety, and clinical benefit. J Clin Oncol. 2004;22(21):4272-4281.

96. Sinkovics JG, Horvath JC. Newcastle disease virus (NDV): brief history of its oncolytic strains. J Clin Virol. 2000;16(1):1-15.

97. Lam KM, Vasconcelos AC, Bickford AA. Apoptosis as a cause of death in chicken embryos inoculated with Newcastle disease virus. Microb Pathog. 1995;19(3):169-174.

98. Janke M, Peeters B, de Leeuw O, et al. Recombinant Newcastle disease virus (NDV) with inserted gene coding for GM-CSF as a new vector for cancer immunogene therapy. Gene Ther. 2007;14(23):1639-1649.
99. Akira S, Takeda K. Toll-like receptor signalling. Nat Rev Immunol. 2004;4(7):499-511.

100. Batliwalla FM, Bateman BA, Serrano D, et al. A 15-year follow-up of AJCC stage III malignant melanoma patients treated postsurgically with Newcastle disease virus (NDV) oncolysate and determination of alterations in the CD8 T cell repertoire. Mol Med. 1998;4(12):783-794.

101. Silberhumer GR, Brader P, Wong J, et al. Genetically engineered oncolytic Newcastle disease virus effectively induces sustained remission of malignant pleural mesothelioma. Mol Cancer Ther. 2010;9(10):2761-2769.

102. Phuangsab A, Lorence RM, Reichard KW, Peeples ME, Walter RJ. Newcastle disease virus therapy of human tumor xenografts: antitumor effects of local or systemic administration. Cancer Lett. 2001;172(1):27-36.

103. Zamarin D, Martinez-Sobrido L, Kelly K, et al. Enhancement of oncolytic properties of recombinant newcastle disease virus through antagonism of cellular innate immune responses. Mol Ther. 2009;17(4):697-706.

104. Shien K, Tanaka N, Watanabe M, et al. Anti-cancer effects of REIC/ Dkk-3-encoding adenoviral vector for the treatment of non-small cell lung cancer. PLoS One. 2014;9(2):e87900.

105. Poirier JT, Dobromilskaya I, Moriarty WF, Peacock CD, Hann CL, Rudin CM. Selective tropism of Seneca Valley virus for variant subtype small cell lung cancer. J Natl Cancer Inst. 2013;105(14):1059-1065.
Oncolytic Virotherapy

\section{Publish your work in this journal}

Oncolytic Virotherapy is an international, peer-reviewed, open access online journal publishing original research, study protocols, reviews, editorials and commentaries on all aspects of oncolytic virology, namely the application of oncolytic viruses for the treatment of cancer. Specific topics in the journal include: Rationale and theoretical aspects of oncolytic virotherapy including in vitro, in vivo and mathematical

\section{Dovepress}

modeling; and practical application and problem solving in the clinic including identification of potential responders through biomarkers and genetic profiling. The manuscript management system is completely online and includes a very quick and fair peer-review system, which is all easy to use. Visit http://www.dovepress.com/ testimonials.php to read real quotes from published authors. 